\title{
An Observation of Inking Behavior Protecting Adult Octopus bocki from Predation by Green Turtle (Chelonia mydas) Hatchlings ${ }^{1}$
}

\author{
Roy L. Caldwell ${ }^{2}$
}

\begin{abstract}
There have been few studies that demonstrate a protective function of inking behavior of cephalopods. In this paper I report the use of ink pseudomorphs by adult Octopus bocki against predatory attacks from green turtle (Chelonia mydas) hatchlings. Turtles that attacked ink pseudomorphs ceased predation attempts whereas naive turtles attacked and ingested octopuses.
\end{abstract}

Animals employ a diversity of behaviors to conceal their identity through camouflage and/or arrested movement, but some take more overt actions to distract and/or interfere with the sensory systems of attacking predators. Such tactics can simply redirect the attack (e.g., the dropping of wriggling tails by lizards [Zani 1996] and arms by octopuses [Norman 1992]); animals can mask their appearance by producing "smoke screens" (the luminescent clouds produced by some deep water shrimp [Widder 1999]); or they can anesthetize or irritate a predator's sensory organs (e.g., spitting of venom by cobras [Wuster and Thorpe 1992], kicking of sand by desert rodents [Randall 1993], release of ink by sea hares [Carefoot et al. 1999]). However, perhaps the best-known use of such tactics involves ink ejection by cephalopods (Hanlon and Messenger 1996).

Most coleoid cephalopods (octopus, squid, and cuttlefish) possess an ink sac and are capable of ejecting a dark, melanistic ink when disturbed. Exceptions include some deepwater cephalopod groups lacking an ink sac and a few shallow-water octopuses that also lack, or have greatly reduced, ink sacs (Mangold 1989). These species typically employ

\footnotetext{
${ }^{1}$ Manuscript accepted 31 March 2004.

${ }^{2}$ Department of Integrative Biology, University of California, Berkeley, Berkeley, California 94720-3140 (phone: 510-642-1391; fax: 510-643-6264; e-mail: 4roy@socrates.berkeley.edu).
}

Pacific Science (2005), vol. 59, no. 1:69-72

(C) 2005 by University of Hawai'i Press

All rights reserved defensive tactics that do not involve the release of ink (Norman 1992). Still, the vast majority of cephalopods that have been observed employ ink release as an apparent defensive tactic (Hanlon and Messenger 1996, Norman 2000).

Inking behavior by cephalopods is generally thought to increase the chance of escape from predators. This can occur in one of three ways, depending on the inking behavior the species employs and the characteristics of the ejected ink. Best known is the release of copious amounts of diffuse ink that provides a visual barrier or "smoke screen" concealing the cephalopod while it escapes from a visual predator (Hanlon and Messenger 1996). Alternatively, ink released in combination with mucus produced by the funnel organ can form a discrete blob. This "pseudomorph" hangs in the water column, creating a false target that can confuse a predator. As the predator attacks or attends to the pseudomorph, the cephalopod jets away (Schäfer 1956, Boletzky 1997). The release of a pseudomorph ink blob may be coupled with a change in the cephalopod's body color after deploying the decoy, which further confuses the predator (Hall 1956). This escape behavior was referred to by Hanlon and Messenger (1996) as the "Blanch-Ink-Jet Maneuver." Finally, it has been suggested that some constituents of cephalopod ink may block and/or irritate the olfactory or taste receptors of predators (MacGinitie and MacGinitie 1968, Moynihan and Rodaniche 1977, Prota et al. 1981, Hanlon and Messenger 1996, Grüninger 1997). The use of ink to disrupt or irritate a predator's sensory receptors does not exclude the possibility that the ink may 
also serve as a smoke screen or pseudomorph defense. Also, not all cephalopod inking episodes are directed only at predators. Cephalopod ink might serve as an alarm pheromone alerting other individuals in the area of danger (in squids, Gilly and Lucero 1992; in cuttlefish, Boal and Golden 1999). Also, Norman (2000) described Broadclub Cuttlefish, Sepia latimanus, inking to enhance an intraspecific agonistic display.

The evolution of octopuses has been strongly influenced by visual predators such as fish, birds, and marine mammals (Wood et al. 2000). It appears to be universally accepted that inking behaviors employed by octopuses protect them by obscuring a predator's view (smoke screen) or by producing a discrete object that distracts or misleads the predator (pseudomorph). Whether octopus ink also effectively blocks or irritates a potential predator's sensory system remains to be proven (Hanlon and Messenger 1996). However, aside from human-octopus interactions and the occasional anecdotal report (e.g., Forsythe and Hanlon 1997), there have been few studies that have attempted to demonstrate a protective function for inking behavior when used by octopuses against predators (but see Grüninger 1997).

While studying Octopus bocki, a small, shallow-water octopus common in French Polynesia, I encountered a local fisherman who had recently discovered a clutch of green sea turtles (Chelonia mydas) hatching. As the hatchlings made their way to the water, they were being devastated by predatory birds, so he collected as many as he could, took them home, and placed them in a tank ( 3 by 1.5 by $0.5 \mathrm{~m}$ ) with flowing seawater. $\mathrm{He}$ hoped to rear the hatchlings until they were large enough to survive release from the natal beach. When I encountered the turtles, they had been in captivity approximately 1 week and had been fed a diet of chopped tuna, cooked pasta, and lettuce. There were approximately 40 individuals in the tank. All appeared healthy, ate when provided food, and spent time alternating floating on the surface and diving to the bottom of the tank. I informed the fisherman that the turtles had to be returned to the wild where they had been collected and he agreed to release them the next day.

To augment their nutrition, I decided to supplement the hatchlings' diet with adult $O$. bocki. I selected an adult male octopus (mantle length approximately $25 \mathrm{~mm}$ ) to offer to the turtles. The turtle tank was in direct sun and there were few shadows. I released the octopus at the surface in the middle of the tank. It immediately began to swim for the bottom but was spotted by a turtle hatchling that rapidly swam toward it. As the turtle neared the octopus (approximately $20 \mathrm{~cm}$ away), the octopus inked twice as it jetted away. Each cloud of ink was dark brown and formed a discrete, filamentous blob, roughly the size of the octopus that produced it. The two pseudomorphs were produced approximately $15-$ $20 \mathrm{~cm}$ apart. The hatchling snapped at the first blob of ink, engulfing a mouthful of the mucus-ink mixture. The turtle immediately stopped, hovered for a few seconds, turned, and slowly swam off. The octopus successfully escaped to the bottom. Within a minute, I released a second, similarly sized octopus near the turtle that had just attacked the pseudomorph. Even though the octopus swam directly in front of it, the turtle made no attempt to capture the octopus.

Over the next hour, I repeated this procedure five more times, each time selecting a different turtle to test using new octopuses. In every case, as the turtle rapidly approached, the octopus inked (usually twice) and jetted away. The turtle invariably attacked one of the ink pseudomorphs and then broke off the attack. None of the turtles that sampled a pseudomorph attacked when the second octopus was presented to it (binomial change test, $n=6, P=0.032$ [Siegel and Castellan 1988]). The octopuses appeared palatable to the turtle hatchlings because several were picked off the pond walls and were eaten by naive turtles before the octopus had a chance to ink or escape.

This experiment was necessarily opportunistic, had a small sample size, and lacked the rigorous control I would have liked. However, it does suggest that young green turtles learn to avoid, or at least not respond to, $O$. bocki after mistakenly attacking a pseudo- 
morph. I do not know how long this experience inhibits attack, but the important point is that it gave the octopus more than enough time to escape.

It is not clear whether the ink-mucus mixture ejected by $O$. bocki was distasteful or irritating to the turtles or simply confused them. Although the turtles immediately stopped their attack when they bit into the pseudomorphs, there were no outward signs of distress except for occasional opening and closing of the mouth. When other turtle hatchlings seized and devoured an octopus from the walls of the tank, none was spat out by the turtles. At least one turtle attacked a second $O$. bocki, suggesting that they were palatable.

Adult green turtles feed primarily on sea grasses and macroalgae, but hatchlings are known to be carnivorous, taking a variety of benthic, shallow-water invertebrates (crustaceans, annelids, cnidarians, and mollusks, including cephalopods) (Seminoff et al. 2000). How frequently $O$. bocki might be encountered by a foraging $C$. mydas is unknown, but the hatchlings certainly could encounter these or other cephalopods that deploy pseudomorph antipredation tactics. From the behavior of the turtles I observed, the ink-blob defense appears to misdirect initial attacks and at least temporarily deter subsequent predation.

The inking behavior exhibited by $O$. bocki was similar to the "Blanch-Ink-Jet Maneuver" described by Hanlon and Messenger (1996). After the release of a puff or two of ink, the octopuses continued to jet away and most lightened in color. Octopus bocki is generally dark brown, and the blanching to a light cream hue was unusual. Once the animals contacted the floor or walls of the dark gray, algal-coated concrete, they immediately changed back to their typical brown color. I did not note any substantial change in texture.

Octopus bocki typically lives within the interstices of coral rubble and algae and is most active at night (Cheng 1996). Although it would be unusual to encounter these octopuses swimming in the water column during the day, this does occasionally happen when the substrate in which they are living is disturbed. This highly stereotyped pattern of inking behavior when caught in the open by a potential predator suggests that the "BlanchInk-Jet Maneuver" is part of their escape repertoire. In this case, it proved to be highly effective against visually directed attacks. I am unaware of any other tests of the effectiveness of octopus pseudomorphs in foiling a predatory attack or inhibiting further attacks.

\section{ACKNOWLEDGMENTS}

I thank R. Anderson, J. Forsythe, and R. Hanlon for helpful comments on early versions of the manuscript.

\section{Literature Cited}

Boal, J. G., and D. K. Golden. 1999. Distance chemoreception in the common cuttlefish Sepia officianalis (Mollusca, Cephalopoda). J. Exp. Mar. Biol. Ecol. 235:307-317.

Boletzky, S. V. 1997. Puffing smoke-rings under water: The functional morphology of cephalopod ink injectors. Vie Milieu 47:180-181.

Carefoot, T. H., S. C. Pennings, and J. P. Danko. 1999. A test of novel function(s) for the ink of sea hares. J. Exp. Mar. Biol. Ecol. 234:185-197.

Cheng, M. A. 1996. The reproductive biology of two species of pigmy octopuses, Hapalochlaena lunulata and Octopus bocki. Ph.D. diss., University of California at Berkeley, Berkeley, California.

Forsythe, J. W., and R. T. Hanlon. 1997. Foraging and associated behavior by Octopus cyanea Gray, 1849 on a coral atoll, French Polynesia. J. Exp. Mar. Biol. Ecol. 209:15-31.

Gilly, W. F., and M. T. Lucero. 1992. Behavioral responses to chemical stimulation of the olfactory organ in the squid Loligo opalescens. J. Exp. Biol. 162:209-229.

Grüninger, T. 1997. The predator-prey relationship between the California moray eel (Gymnothorax mordax) and the two-spotted octopus (Octopus bimaculoides). M.S. thesis, University of San Diego, San Diego, California. 
Hall, D. N. F. 1956. Ink ejection by Cephalopoda. Nature (Lond.) 177:663.

Hanlon, R. T., and J. B. Messenger. 1996. Cephalopod behaviour. Cambridge University Press, Cambridge.

Mangold, K. 1989. Traite de zoologie: Cephalopoda. Tome V, Fascicule 4. Masson, Paris.

MacGinitie, G. E., and N. MacGinitie. 1968. Natural history of marine animals. 2nd ed. McGraw-Hill, New York.

Moynihan, M. H., and A. F. Rodaniche. 1977. Communication, crypsis and mimicry among cephalopods. Pages 293-302 in T. A. Sebeok, ed. How animals communicate. Indiana University Press, Bloomington.

Norman, M. D. 1992. Ameloctopus litoralis, gen. et. sp. nov. (Cephalopoda: Octopodidae), a new shallow water octopus from Australian waters. Invertebr. Taxon. 6: $567-582$.

. 2000. Cephalopods: A world guide. ConchBooks, Hackenheim.

Prota, G., J. P. Ortonne, C. Voulot, C. Khatchadourian, G. Nardi, and A. Palumbo. 1981. Occurrence and properties of tyrosinase in ejected ink of cephalopods. Comp. Biochem. Physiol. B Comp. Biochem. 68:414-419.

Randall, J. A. 1993. Behavioural adaptations of desert rodents (Heteromyidae). Anim. Behav. 45:263-287.

Schäfer, W. 1956. Die Schutzwirkung der Tintenfisch-Tinte. Nat. Volk (Frankf.) 86:24-26.

Seminoff, J. A., W. J. Nichols, and A. R. S. Hidalgo. 2000. Chelonia mydas agassizii (East-Pacific green turtle): Diet. Herpetol. Rev. 31:103.

Siegel, S., and N. J. Castellan. 1988. Nonparametric statistics for the behavioral sciences. McGraw-Hill, New York.

Widder, E. A. 1999. Bioluminescence. Pages 555-581 in S. N. Archer, M. B. A. Djamgoz, E. R. Loew, J. C. Partridge, and S. Vallerga, eds. Adaptive mechansims in the ecology of vision. Kluwer Academic Publishers, Dordrecht.

Wood, J. B., C. L. Day, P. G. Lee, and R. K. O'Dor. 2000. CephBase: Testing ideas for cephalopod and other species-level databases. Oceanography 13:14-20.

Wuster, W., and R. S. Thorpe. 1992. Dentitional phenomena in cobras revisited: Spitting and fang structure in the Asiatic species of Naja (Serpentes: Elapidae). Herpetologica 48:424-434.

Zani, P. A. 1996. Patterns of caudal-autotomy evolution in lizards. J. Zool. (Lond.) 240:201-220. 